\title{
Development of an HLFS agricultural tire model using FEA technique
}

\author{
Zeinab El-Sayegh $^{1}$ (D) $\cdot$ Mirwais Sharifi $^{1} \cdot$ Fatemeh Gheshlaghi $^{1} \cdot$ Aref Mardani $^{2}$
}

(c) Springer Nature Switzerland AG 2019

\begin{abstract}
This paper proposes a new high lug farm service (HLFS) agricultural tire size 220/70B16 tread design used for off-road agricultural operation. The HLFS tire is modeled using finite element analysis (FEA) technique in Visual Environment's Pam-Crash software. The HLFS tire is designed using a combination of different materials including the Mooney-Rivlin material for tread. The Mooney-Rivlin material is an hyper-elastic material and it accurately resembles the mechanics and behavior of rubber used in tires. The FEA tire model is then validated against manufacturer's provided data for several tire characteristics including radial, lateral, and tangential stiffness. This research will further continue to investigate the HLFS tire performance over clayey loam for different operating conditions.
\end{abstract}

Keywords Tire modeling · Finite element analysis · Vibration · Computational mechanics · Agricultural tire · Off-road dynamics

\section{Introduction}

Agricultural tires have been a predominant research topic since the 1900's. The wheels were originally made using hard steel material and were used in very rough and irregular terrain. The steel wheels caused lots of vibrations and provided a very harsh ride for the tractor operators. Due to the intense competition of tire manufacturers in designing more efficient tires with lower costs, the use of finite element tools has been greatly enhanced.

Since 1970s, finite element method (FEM) was first used to predict elastic-plastic deformation that experimental methods or traditional analytical models could not be accurate because of the complex structure of rubber tires.

In 1973, Zorowski [1] proposed the use of finite element analysis for studying the dynamic behavior of a tire. Subsequently in 1974, Ridha [2] developed a linear finite element method to design a tire mold. This mold is used to investigate the tire deformation after shrinkage. The results of this analysis were acceptable in comparison with an actual tire behaves. In 1984, Tielking [3] used a three-dimensional FEA model to develop a four-ply bias tire to predict the interaction between tire and ground Hard Surface). In 1994, Hu et al. [4] used FEA to model a $2 \mathrm{D}$ agricultural tire. They considered that tire deformation and the contact pressure change based on the bead, sidewall, tread and lugs properties. Analogous procedures by Burke et al. [5] and Shoop [6] have been also established.

In 2006, Chae [7] has used nonlinear finite element analysis to model and analyze a nonlinear three-dimensional FEA truck tire model. In 2008, Mohsenimanesh et al. [8] modeled a tractor tire based on the contact pressure distribution between off-road tire and road considering the inflation pressure and vertical load. They proposed a non-linear multi-laminated FEA model which includes the structural geometry, the anisotropic substance attributes of the multiple layers and the approximately incompressible exclusivity of the tread rubber district. Their results displayed that less damage to the road occurs when the tire contact pressure distribution isn't concentrated at the center of the contact patch. This model was useful for reasonable predictions of the tractor tire -road interaction.

\footnotetext{
$\triangle$ Zeinab El-Sayegh, Zeinab.El-Sayegh@uoit.ca; Mirwais Sharif, mirwais.sharifi@uoit.net; Fatemeh Gheshlaghi, Fatemeh.Gheshlaghi@ uoit.ca; Aref Mardani, A.mardani@urmia.ac.ir | ${ }^{1}$ Ontario Tech University, 2000 Simcoe St N, Oshawa, ON L1G 0C5, Canada. ${ }^{2}$ Urmia University, Nazloo Roa, Urmia 571531177, Iran.
} 
Later in 2013, Ali et al. [9] suggested an FEA technique for a truck tire-soil interaction, the tire was modeled using PamCrash and was validated by vertical stiffness and footprint area various tests.

Later in 2009-2010, Allen [10], Slade [11] , Lescoe [12] and Dhillon [13] predicted the transient responses of a pneumatic truck tire and cornering test simulations using Pam-Crash. To this aim, they developed a three dimensional element model for track tire using Pam-Crash and represented a three-layered membrane element for the carcass and belt plies. Recently in 2018, Zeinab et al. [14-16] modeled tires for on-road and off-road operations to determine tire characteristics such as rolling resistance, traction, and cornering on different terrains.

In this paper a new agricultural tire model size 220/70B16 for off-road operation purposes is modeled and validated. The tire is modeled using FEA technique and several material properties provided from manufacturer and research. The tire is validated in vertical, lateral, and tangential response against manufacturer data provided. The tire will be further used to develop a tire-clayey loam model for prediction of performance and effect of several operating conditions on tire-terrain interaction.

\section{FEA tire modelling}

The HLFS tire model was designed in reference to an FEA model of the off-road Michelin Stryker tire that was previously modeled and validated in previous research work [17]. The FEA Michelin tire size 12R20 was scaled in all directions to match the size of the HLFS tire as a 220/70B16.

\subsection{FEA lug design}

A single lug was designed on the bald tire by first creating nodes which covered the lug's dimensions. The lug is 140 $\mathrm{mm}$ long, $25 \mathrm{~mm}$ wide at the contact patch and has $30 \mathrm{~mm}$ depth. It was found that the connection between the bald tread and the lugs were stronger and more well connected by ensuring there were maximum possible nodes on the bald tread which coincided with the nodes created for the lugs. Furthermore, the lug's wireframe was designed by creating nodes at the corners of the upper portion of the lug. Afterwards, solid elements were created by connecting 6 nodes using the three-dimensional node option. The designed hexa solid elements were then re-meshed into a finer mesh in order to insure accuracy in the contact algorithm calculation. Since the lugs have an offset of $8^{\circ}$ on each side, another lug was created on the opposite side with an 8-degree rotation about the tire $y$-axis from the initial lug using a similar methodology.
The single lugs designed on both sides of the tractor tire were then rotated 19 times about the tire center using an angle of $18^{\circ}$. This created the full HLFS tire tread with a total of 40 lugs equally spaced out between each other. The nodes created on the surface of the bald tread due to these lugs are now duplicated due to the rotation of the lugs. All coincident nodes for which the maximum gap was less than $0.1 \mathrm{~mm}$ were eliminated and fused. This ensured that the coincident nodes between the lugs and the bald tread were the only ones found in the check. These coincident nodes were then fused in to one node as to create a fully connected tread pattern.

Mooney-Rivlin material was assigned to the designed tread. Research indicates that this material best describes many plastic elastomers which includes natural rubber [18].

\subsection{HLFS tire construction}

The new design is modeled according the HLFS Tire made by Barez Tires [19] and is seen in Fig. 1. The HLFS tire has the dimensions of 220/70B16 and has a bias ply body. The tire width is $220 \mathrm{~mm}$, and the outer diameter is $840 \mathrm{~mm}$, the rim width is $406 \mathrm{~mm}$. The tread portion is made of a total of 42 lugs. Each lug is $139 \mathrm{~mm}$ in length, $25 \mathrm{~mm}$ in width, and has a depth of $30 \mathrm{~mm}$. The lug angle with the transverse $y$-axis is $34 \circ$. The tire has a total mass of $37.2 \mathrm{~kg}$.

The HLFS tire is designed using the Visual Environment's Pam-Crash application from ESI Group. A previously modeled and validated off-road Michelin Stryker [17] tire was used as a basis for the HLFS tire design. The HLFS tire is made of 21 parts which make up the rim, tread, under tread, layered belts plies, and sidewalls.

The HLFS tire is meshed using different elements for each part. The rim is created using Quad shell elements. The lugs and the under tread are created using solid hexa elements. The tread base is part of the whole tread design and is what the lugs are attached to. They are created using
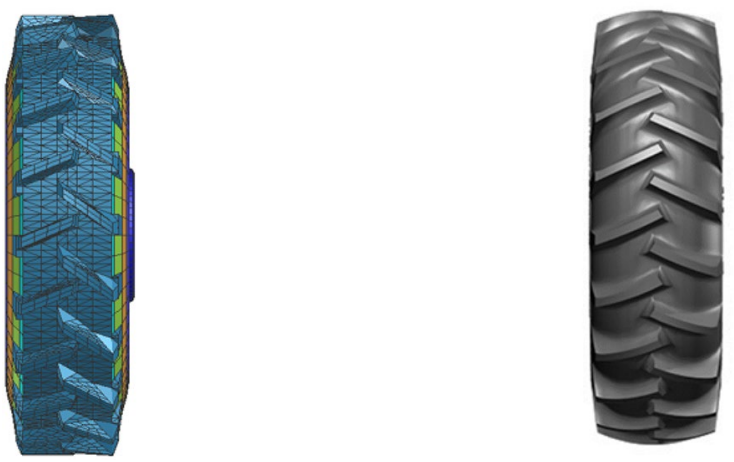

Fig. 1 The HLFS agricultural tire made by Barez Tires [19] and its model in Pam-Crash 
a Degen tetra solid elements. The tire shoulder is made from solid penta elements. The sidewall layers and plies are all created using a membrane quad element. Lastly, the beads are created using beam elements to have them act very rigid. A section cut for the HLFS tire is created using these elements and rotated to create the full tire.

The rim consists of 1 rigid part, sidewall consists of 13 parts, the layered belts and plies have 4 parts, 1 tread, 1 under tread and 1 shoulder part. The rim shown in Fig. 2 is considered a rigid part where it does not experience any deformation when loads are applied to it. The center of the rim is considered the center of the tire and all forces are applied at the center.

Figure 3 shows the modeled HLFS agricultural tire, the tire is scaled as 1:1 in accordance to the dimensioned mentioned above for the actual HLFS tire. The tread is made of a Mooney Rivlin Solid and best represents the rubber material used in tractor tires. It has a mass density of $1225 \mathrm{~kg} / \mathrm{m}^{3}$ [7]. It also has a first Mooney-Rivlin law coefficient of 0.67 , and a second Mooney-Rivlin Law coefficient of 2.46 and a Poisson's ratio (loading) of 0.46 . The Mooney-Rivlin coefficients are obtained from a previous research for off-road tires [7].

The under tread is also made of a Mooney-Rivlin Solid with mass density of $1224 \mathrm{~kg} / \mathrm{m}^{3}$, first and second Mooney-Rivlin law coefficients of 0.051 and 0.186 , and a poison's ratio of 0.49 .

The tire sidewall is made of multiple layered membrane with one isotropic parent sheet and two fiber layers. The mass density for the whole sidewall is $1496 \mathrm{~kg} / \mathrm{m}^{3}$. The parent sheet has a Young's modulus of $800 \mathrm{MPa}$ and a Poisson's ratio of 0.46 . The first and second fiber layers have a Young Modulus and a shear modulus of $800 \mathrm{MPa}$ and 1 MPa respectively Fig. 4.

Tables 1, 2, 3, 4 shows the material properties of the FEA tire parts and layers. There are 6 layers of belt plies in the tire carcass. These correspond to a density of $1496 \mathrm{~kg} / \mathrm{m}^{3}$, Poisson's ratio of 0.46 and a parent sheet Young's modulus of $1 \mathrm{MPa}$. The first fiber layer has a Young's modulus of 1 $\mathrm{MPa}$ and a shear modulus of $600 \mathrm{MPa}$. The second fiber layer has a Young's modlus of $1 \mathrm{MPa}$ and a shear modulus of $600 \mathrm{MPa}$. The beads are made of beam elements and has

Fig. 2 Rigid body constraint applied to the HLFS tire's rim

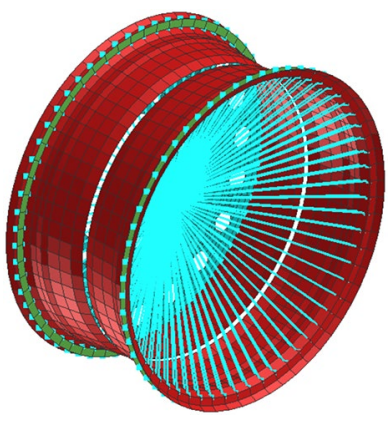

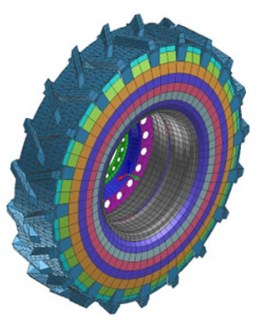
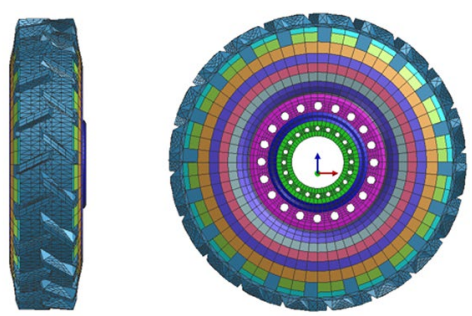

Fig. 3 The HLFS agricultural tire and rim assembly

a density of $23,700 \mathrm{~kg} / \mathrm{m}^{3}$, a Poisson's ratio of 0.4 , a Young's modulus of $92.31 \mathrm{GPa}$ and a yield stress of $1 \mathrm{E} 20 \mathrm{MPa}$.

The rim is made of a null shell material and has a mass density of $800 \mathrm{~kg} / \mathrm{m}^{3}$, a Young's modulus of $200 \mathrm{GPa}$ and a poisons ratio of 0.3 . The total mass of the tire using the mass inertia data was found to be $38 \mathrm{~kg}$. This accurately represents the actual tire model's weight with a percent error of $2.1 \%$.

\section{FEA tire validation}

The FEA tire model is further validated against the tire characteristics provided by the manufacturer. The drumcleat test is first performed to determine the first mode of vibration of the tire that is then used to calculate the damping ratio. Later, four different tests are performed to determine the vertical, lateral, and tangential characteristics of the tire.

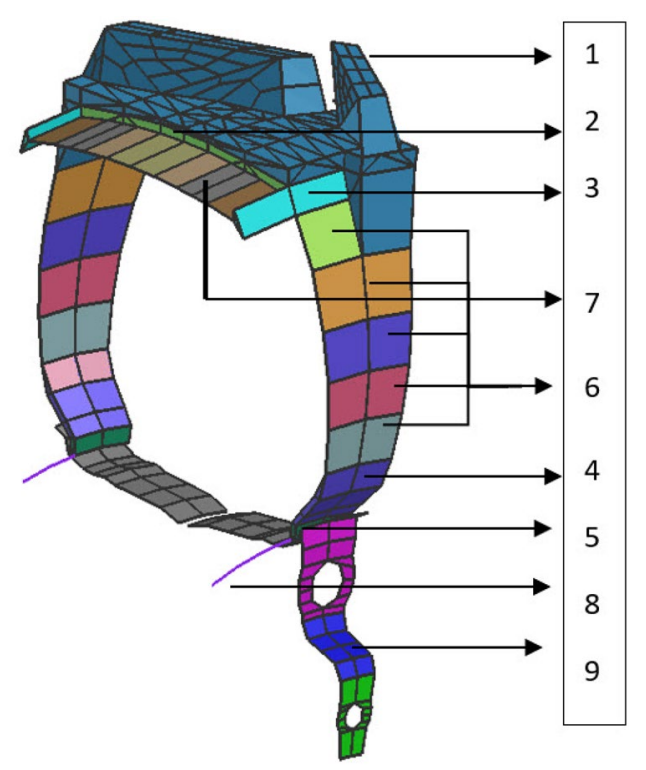

Fig. 4 FEA tire section cut with numbers 
Table 1 Material properties of the Mooney-Rivlin rubber solid elements

\begin{tabular}{llllll}
\hline Tire component & Tread & Under tread & Shoulder & Sidewall & Sidewall \\
\hline Material I.D & 1 & 2 & 3 & 4 & 5 \\
Density (ton/mm $\mathrm{mm}^{3}$ ) & $1.39 \mathrm{E}-9$ & $5.962 \mathrm{E}-10$ & $1.35 \mathrm{E}-9$ & $8.81 \mathrm{E}-10$ & $8.82 \mathrm{E}-10$ \\
1st Mooney-Rivlin coefficient (C10) & 0.67 & 0.051 & 0.67 & 0.0392 & 0.0392 \\
2nd Mooney-Rivlin coefficient (C01) & 2.46 & 0.186 & 2.46 & 0.1268 & 0.1268 \\
Poisson's ratio & 0.49 & 0.499 & 0.499 & 0.499 & 0.499 \\
\hline
\end{tabular}

Table 2 Material properties of the membrane elements

\begin{tabular}{lll}
\hline Tire component & Sidewall & Plies \\
\hline Material I.D & 6 & 7 \\
Density (ton $/ \mathrm{mm}^{3}$ ) & $1.65 \mathrm{E}-9$ & $1.85 \mathrm{E}-9$ \\
Isotropic parent sheet Young's modulus (MPa) & 800 & 1 \\
Isotropic parent sheet Poisson's ratio & 0.46 & 0.46 \\
Layer 1 Young's modulus (MPa) & 800 & 1 \\
Layer 1 Shear modulus (MPa) & 1 & 600 \\
Later 1 angle of fibers with R-axis & $0^{\circ}$ & $0^{\circ}$ \\
Layer 2 Young's modulus (MPa) & 800 & 1 \\
Layer 2 Shear modulus (MPa) & 1 & 600 \\
Layer 2 angle of fibers with R-axis & $90^{\circ}$ & $90^{\circ}$ \\
\hline
\end{tabular}

Table 3 Material properties of the membrane elements

\begin{tabular}{ll}
\hline Tire component & Beads \\
\hline Material I.D & 8 \\
Density (ton $/ \mathrm{mm}^{3}$ ) & $2.37 \mathrm{E}-8$ \\
Young's modulus (GPa) & 92.31 \\
Poisson's ratio & 0.4 \\
Yield stress (MPa) & $1 \mathrm{E} 20$ \\
\hline
\end{tabular}

Table 4 Material properties of the shell elements

\begin{tabular}{ll}
\hline Tire component & Rim \\
\hline Material I.D & 9 \\
Density (ton $/ \mathrm{mm}^{3}$ ) & $8 \mathrm{E}-9$ \\
Young's modulus (GPa) & 200 \\
Poisson's ratio & 0.3 \\
\hline
\end{tabular}

\subsection{Validation techniques}

The Drum-Cleat test shown in Fig. 5 is used to determine the first mode of vibration of the tire. The drum-cleat consists of a drum of $2.5 \mathrm{~m}$ radius with a single semi-circular cleat of $15 \mathrm{~mm}$ radius. The tire is placed on top of the drum and it is constrained in lateral and longitudinal translation and rotation about the vertical and longitudinal axis. The tire is first inflated to the desired inflation pressure, then a constant vertical load is applied to the center of the tire and the tire is allowed to settle on the drum. Then, an the desired

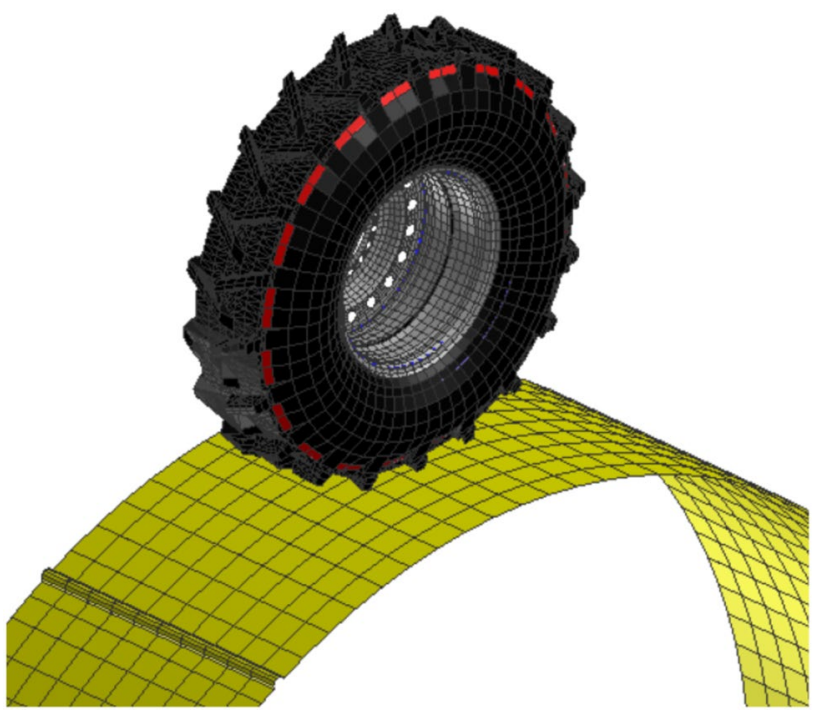

Fig. 5 FEA tire-drum-cleat model

angular velocity is applied to the center of the drum which excites the tire and allows for the calculation of the vertical first mode of vibration.

The vertical force generated between the tire and the drum is extracted in time domain and the converted into frequency domain. The first vertical mode of vibration is found at the second highest peak of the vertical force versus frequency curve and its corresponding frequency in Hertz is obtained. This frequency is used to calculate the sidewall damping coefficient.

The vertical force as a function of time during the simulation is extracted and the fast Fourier transformation (FFT) function implemented in Pam-Crash is used to transform from time domain to frequency domain. The variation of the vertical force as a function of frequency in $\mathrm{Hz}$ after applying the FFT is then plotted, the first peak corresponds to the frequency at which the rotation of the tire occurs, while the second peak corresponds to the frequency which represents the first mode of vibration. The sidewall damping coefficient, $\alpha$ is then calculated using Eq. 1 Where $\omega$ is the first mode of vibration frequency in rad/s and $\xi$ is the critical damping which is estimated to be $5 \%$ for tires based on previous study [7].

\section{SN Applied Sciences}




$$
\alpha=\frac{2 \xi \sqrt{K M}}{M}=2 \xi \sqrt{\frac{K}{M}}=2 \xi \omega
$$

The damping is added to the tire's sidewall through the application of a damping load through the structural loads application within Pam-Crash. As a result, the damping is added through a load instead of the material properties itself. There are two ways of adding damping within this application; using a nodal factor or a curve. Damping is added to the sidewall using a mass proportional nodal damping coefficient also known as the nodal factor that is calculated using Eq. 1. The sidewall is selected for the parts to be used where nodal damping is added to the sidewall. This sidewall damping is maintained throughout the full simulation.

The first validation test shown in Fig. 6 depicts the vertical deflection test performed on a hard surface. This test is used to determine the vertical stiffness of the tire when subjected to a ramp load. The HLFS tire is placed on top of a rigid road, the tire is constrained in the lateral and longitudinal translational motion and in all rotational direction. The tire is first inflated to the desired inflation pressure then a ramp load is applied to the center of the tire. The vertical force along with the vertical deflection of the tire with respect to time are extracted and plotted to determine the vertical stiffness. The slope of vertical force as a function of the vertical displacement is regarded as the vertical stiffness. Fig. 6 shows the normal displacement in the tire sidewall elements during the vertical stiffness test, it is notices that the lower part of the sidewall which is closest to the contact surface has the highest displacement value recorded to be $41.8 \mathrm{~mm}$.

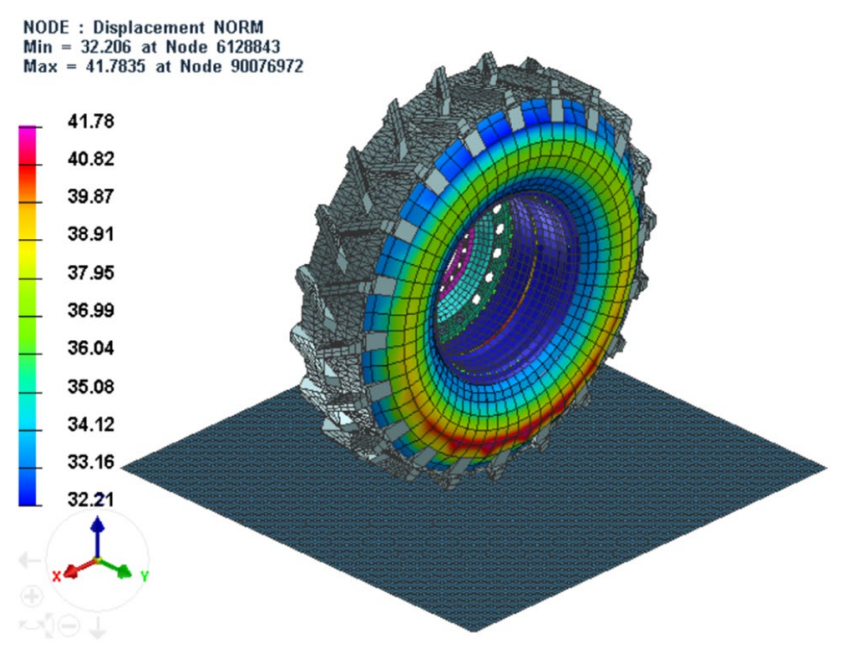

Fig. 6 Normal displacement in tire sidewall during vertical stiffness test
The lateral stiffness test is then performed to determine the lateral stiffness of the HLFS tire at a vertical load of $5895 \mathrm{~N}$, lateral load of $400 \mathrm{~N}$, and an inflation pressure of $193 \mathrm{kPa}$. The tire is first inflated to $193 \mathrm{kPa}$, and then a constant vertical load of $5895 \mathrm{~N}$ is applied to the center of the tire. Once the tire is stable on the ground, a lateral load of $400 \mathrm{~N}$ is applied to the center of the tire until a steady state lateral displacement is achieved. Then, the lateral load is removed, and the tire is allowed to oscillate in lateral direction until steady state is achieved again. The initial steady state displacement obtained from the simulations is used in Eq. 2 to determine the lateral tire stiffness. Where the lateral force is that applied to the center of the tire and is equal to $400 \mathrm{~N}$.

$k_{l}=\frac{\text { Lateral force }(\mathrm{N})}{\text { Lateral displacement }(\mathrm{mm})}$

The longitudinal test is then used to determine the longitudinal stiffness of the tire. The tire is first inflated to 193 $\mathrm{kPa}$, then a constant vertical load of $5898 \mathrm{~N}$ is applied to the center of the tire. Upon contact, a longitudinal force of $1500 \mathrm{~N}$ is applied to the tire's center of gravity. The load is held until steady state longitudinal displacement is achieved and released enabling the tire to reach initial steady state conditions once again. The longitudinal force along with the translational and rotational velocities are extracted from the simulation. The slip is then calculated using Eq. 3, and the longitudinal force as a function of slip (\%) is plotted. The slope of the longitudinal force versus slip at approximately $0 \%$ slip is regarded as the longitudinal tire stiffness as shown in Eq. 4.

Longitudinal slip $\left.\right|_{\text {traction }}=\left(1-\frac{v}{r \omega}\right) \times 100$

$k_{k}=\left.\frac{\partial \text { Longitudinal force }}{\partial \text { Slip }}\right|_{\text {at zero slip }}\left(\frac{\mathrm{N}}{\text { Unit slip }}\right)$

In order to calculate the longitudinal tread stiffness $k_{c x}$, the longitudinal tire stiffness, $k \mathrm{k}$ is divided by half the projected contact length a, as shown in Eq. 5. The projected contact length a corresponds to the length of the HLFS tire which is in contact with the ground.

$k_{c x}=\frac{k_{k}}{a}\left(\frac{\mathrm{N}}{\mathrm{mm}}\right)$

\section{Results and discussions}

The results of the tests descried in Sect. 3 are presented and discussed in this section. 


\subsection{Drum-cleat test}

The drum-cleat test was first performed with a preliminary damping coefficient based on previous research. The vertical force as a function of time is extracted from the simulation and the FFT filter employed within Pam-Crash was used to determine the vertical force as a function of frequency as shown in Fig. 7.The first mode of vibration for the HLFS tire was found to be at a frequency of $82 \mathrm{~Hz}$, which is within the acceptable range for agricultural tires. Based on the estimated frequency the sidewall damping coefficient was then calculated to be 51.5 .

Table 5 shows the damping coefficient at several operating conditions. From Table 5, it shows that there is an increase in damping coefficient as the inflation pressure increased at a drum cleat's rotational speed of 5.55 $\mathrm{rad} / \mathrm{s}$ and a vertical load of $10,000 \mathrm{~N}$. This is because the frequency at which the first mode of vibration occurs, increases as the inflation pressure of the tire increases. For a drum cleat with a rotational speed of $11.1 \mathrm{rad} / \mathrm{s}$, the damping coefficients do not vary much with the change of inflation pressure. Under inflation and over inflation both require damping coefficients similar to operating inflation pressure. This means at higher speeds the tire is not sensitive to changes in inflation pressure in regards to the damping coefficients used for the simulations.

\subsection{Vertical stiffness test}

The vertical force as a function of the vertical deflection for both measurement and simulation at $103 \mathrm{kPa}$ inflation pressure is shown in Fig. 8. The slope of the vertical force versus vertical deflection represent the vertical stiffness, $k_{\text {tot }}$. It is recorded that the measured and simulated vertical stiffness are $250 \mathrm{~N} / \mathrm{mm}$ and $422 \mathrm{~N} / \mathrm{mm}$, respectively. Furthermore, it is observed that for a small deflection of

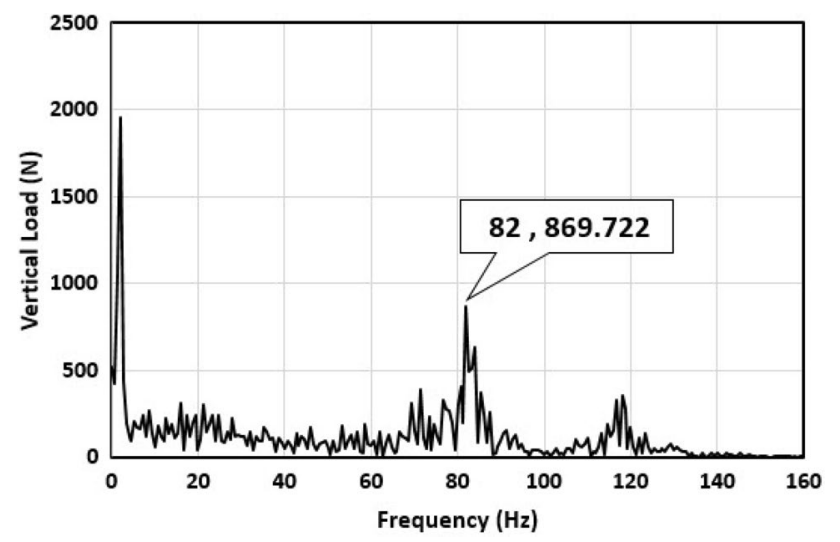

Fig. 7 HLFS tire at $193 \mathrm{kPa}$ inflation pressure and $5895 \mathrm{~N}$ vertical load

SN Applied Sciences
Table 5 Material properties of the shell elements

\begin{tabular}{lll}
\hline $\begin{array}{l}\text { Inflation } \\
\text { pressure } \\
(\mathrm{kPa})\end{array}$ & $\begin{array}{l}\text { Damping coefficients } \\
\text { at } 5.55 \mathrm{rad} / \mathrm{s} \text { rotational } \\
\text { speed }\end{array}$ & $\begin{array}{l}\text { Damping coefficients at } \\
11.1 \mathrm{rad} / \mathrm{s} \text { rotational speed }\end{array}$ \\
\hline 103 & 28.5 & 52.3 \\
193 & 51.5 & 51.5 \\
275 & 58 & 52.8 \\
\hline
\end{tabular}

less than $6 \mathrm{~mm}$ both simulations and measurements are

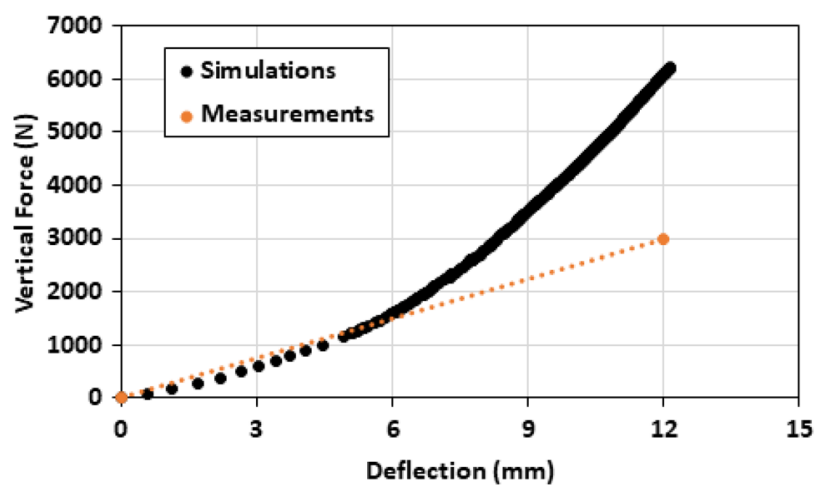

Fig. 8 Vertical force as a function of frequency and deflection

in good agreement and have almost the same behavior. For a deflection greater than $6 \mathrm{~mm}$ or a force greater than $2 \mathrm{kN}$ the simulation and predicted values are different, and the simulation adhere a non-linear behavior.

It should be noted that generally the agricultural tires operate at low vertical loads generally less than $3 \mathrm{kN}$. Thus, the FEA tire model is considered to have a good behavior at normal operating conditions and requires further investigation at higher operating loads.

Furthermore, the vertical stiffness increases as the inflation pressure increases past $193 \mathrm{kPa}$ (28 psi) or at the operating inflation pressure for the tire. The underinflated tire shows increased stiffness also. The simulated vertical stiffness at 103, 193, $275 \mathrm{kPa}(15,28$ and 40 psi) gave stiffness of $525.92,422.14$ and $448.13 \mathrm{~N} / \mathrm{mm}$, respectively. The results show that for both over inflation $275 \mathrm{kPa}$ (40 psi) and under inflation $103 \mathrm{kPa}(15 \mathrm{psi})$ the tire gets stiffer. The underinflated tire shows similar stiffness for a range of $6 \mathrm{~mm}$ deflection when compared to both the $193 \mathrm{kPa}$ (28 psi) and $275 \mathrm{kPa}$ (40 psi) tires. As the vertical force is increased past $3000 \mathrm{~N}$ and the tire has passed $6 \mathrm{~mm}$ deflection, the tire inhibits very stiff characteristics as the tire cannot compress vertically as easily. The vertical force will need to be increased a lot to deflect the side rubber of the tire. This sidewall rubber is very tough as the real life tire exhibits these characteristics as well. 


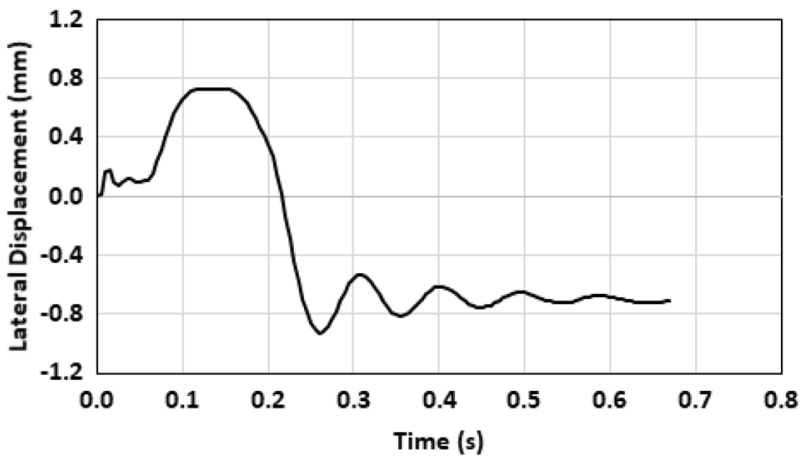

Fig. 9 Lateral displacement as a function of time during lateral test

\subsection{Lateral stiffness test}

Figure 9 shows the variation of the lateral displacement as a function of time at $400 \mathrm{~N}$ lateral force and $193 \mathrm{kPa}$ inflation pressure. The computed lateral stiffness, $k_{l}$ is $288 \mathrm{~N} /$ $\mathrm{mm}$ while the measured on is $305 \mathrm{~N} / \mathrm{mm}$. Thus, the error is around 5\% which shows an agreement between the simulation and measurement results.

\subsection{Longitudinal stiffness test}

Figure 10 shows the variation of the longitudinal displacement as a function of the time at $1500 \mathrm{~N}$ longitudinal force and $193 \mathrm{kPa}$ inflation pressure during the longitudinal stiffness simulation. The longitudinal stiffness, $k_{c x}$ is computed to be $300 \mathrm{~N} / \mathrm{mm}$ while the measured one is $302 \mathrm{~N} /$ $\mathrm{mm}$. Thus, the error is calculated to be around 1\%. Therefore, the simulated and measurement results are in good agreement.

Figure 11 shows the displacement in the longitudinal direction on the FEA tire at $1500 \mathrm{~N}$ longitudinal load and $193 \mathrm{kPa}$ inflation pressure. The highest recorded displacement is around $9.5 \mathrm{~mm}$ at the front side of the tread and the lowest recorded displacement is around zero $\mathrm{mm}$ at

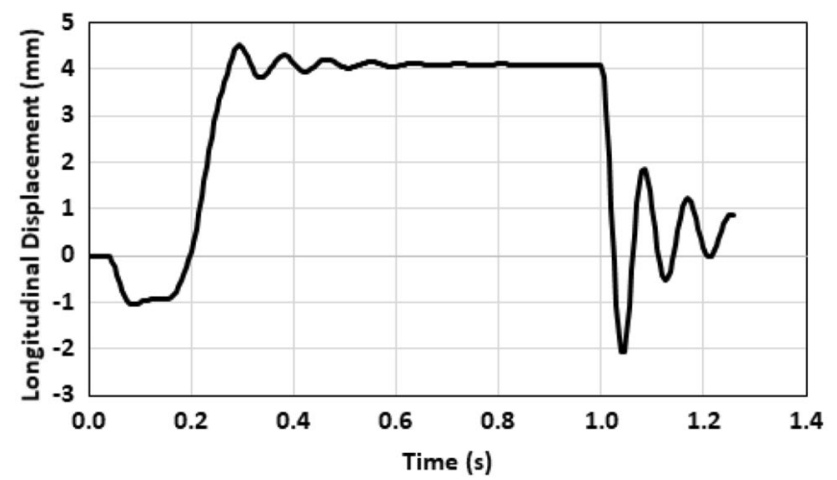

Fig. 10 Longitudinal displacement during langential test

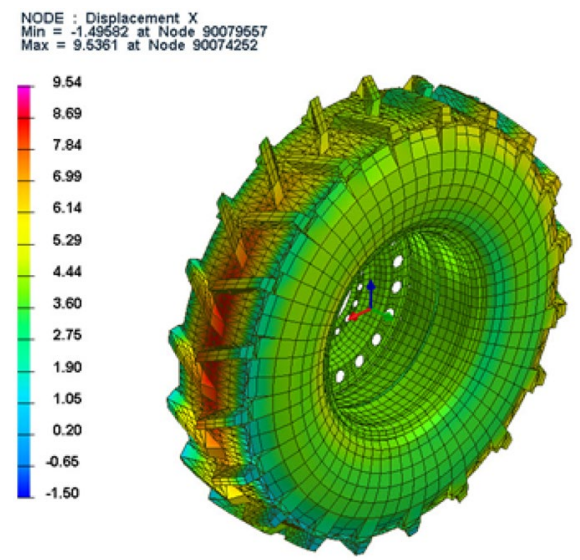

Fig. 11 Longitudinal displacement on the tire at $1500 \mathrm{~N}$ and 193 $\mathrm{kPa}$ inflation pressure

the sidewall of the tire. It is also noticed since the rim is constrained and is considered as a rigid body; thus, it has no displacement as well.

\section{HLFS tire-terrain interaction}

The HLFS tire model is used in further analysis over an SPH clayey loam model. The clayey loam model is modeled and calibrated in [20]. The calibration of such a soil is performed using the pressure-sinkage and shearstrength tests. The soil characteristics are validated against measurements performed in a laboratory under similar conditions.

\subsection{SPH soil model}

Clay loam soil properties obtained by empirical tests are used to calibrate the SPH soil. Experimental tests for calculating the pressure-sinkage and shear-strength parameters are described in [21]. In order to model SPH soil, 6 boxes with dimensions of $600 \times 800 \times 600 \mathrm{~mm}$ filled with SPH particles are used in Pam-Crash software environment. The pressure-sinkage test is performed using loaded plates on each soil box and the sinkage values are compared with the experimental values. At a pressure of about $80 \mathrm{kPa}$, the experimental sinkage value in clay loam soil is $47 \mathrm{~mm}$, which is well approximated for the simulated SPH soil of $41.3 \mathrm{~mm}$.

Another test for soil calibration is shear-strength test shown in Fig. 12, which uses the direct shear box. The top box is moved at a speed equal to the speed of the experimental tests $(0.2 \mathrm{~m} / \mathrm{s})$. The pressures corresponding to the pressures applied in the experimental tests are applied to 


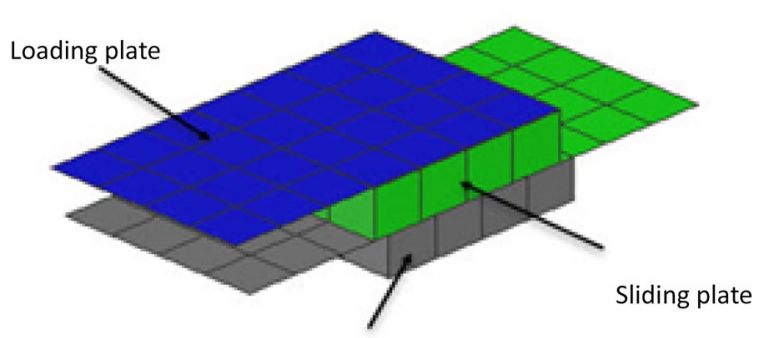

Fixed plate

Fig. 12 Schematic of the shear-strength simulation setup

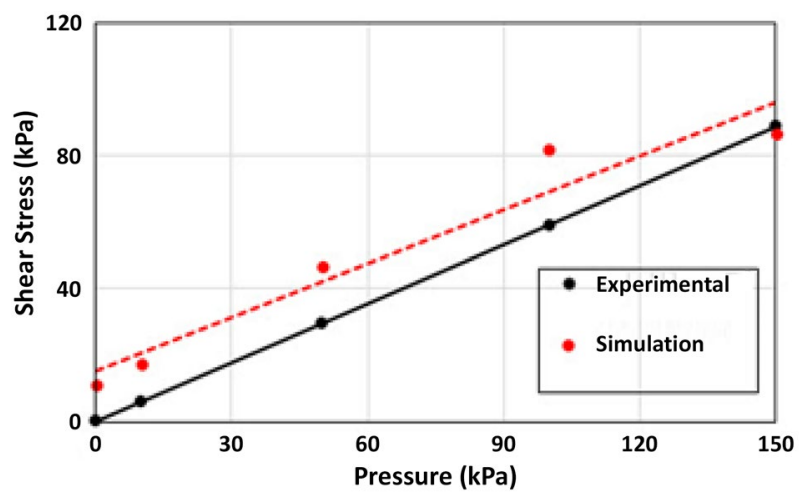

Fig. 13 Shear- strength results for experimental and simulation data

the loading plate and finally the results of shear stresses are compared with the experimental values.

Figure 13 shows the relationship between shear stress and pressure for measurement and simulation data. The slope of the shear stress-pressure diagram shows the angle of internal friction and the y-intercept shows the soil cohesion. The angle of internal friction and cohesion for simulation data are $28.42^{\circ}$ and $0.35 \mathrm{kPa}$, respectively, and these values for measurements are $30.51^{\circ}$ and $15.14 \mathrm{kPa}$, respectively. The parallelism of the two shear stress-pressure curves provides clear evidence of the acceptable prediction for simulation model at the internal friction angle. It is noteworthy that the difference in cohesion values for the simulation data and measurements is one of the limitations of the simulation, however for vehicle operations the angle of shear resistance is considered sufficient.

\subsection{Off-road energy loss}

The simulation setup consists of a box filled with SPH clayey loam soil particles and the FEA tire on top. The dimensions of the soil bin are $7000 \times 712 \times 560 \mathrm{~mm}$ (length $\times$ width $\times$ depth). The selected value for the length of the soil bin is important to provide sufficient pathway for stability in the interaction between the soil and the tire. The depth of the bin is selected to avoid tire penetration into the ground of the box. The total number of SPH particles in each soil bin is 221,184 particles with a particle smoothing length to radius ratio of 1.2 , a minimum smoothing length of 1 and a maximum smoothing length of 100 , the values of the SPH part are chosen based on previous sensitivity analysis [20].

A contact between the tire and soil is created using node-symmetric node-to-segment contact with edge treatment. The contact has a coefficient of friction of 0.6 and a thickness of $5 \mathrm{~mm}$. Another contact between the box and the SPH clayey loam is created to prevent the particles from falling off the box. It should be noted that the contact parameters are chosen based on recommendation provided by the software providers [22].

The tire is first inflated to the desired inflation pressure, then the desired vertical load is applied to the center of the tire. After allowing the tire to stabilize on the soil, a longitudinal constant velocity off $1 \mathrm{~m} / \mathrm{s}$ is applied to the center of the tire allowing the tire to freely roll over the clayey loam soil. The simulation runs for $4 \mathrm{~s}$ which allows the forces to reach steady state.

The distance traveled and the longitudinal force on the contact patch between the tire and the soil are computed at $4 \mathrm{~s}$ of simulation time. The simulation is repeated at different operating conditions, including several vertical loads and inflation pressures. The rolling resistance force or the longitudinal force which is extracted from the output file for a simulation where an inflation pressure and vertical load of $40 \mathrm{psi}$ and $9000 \mathrm{~N}$ respectively is shown in Fig. 14. It can be seen that the forces have some noise at around $1.5 \mathrm{~s}$ into the simulation but tend to oscillate around a mean value after $1.5 \mathrm{~s}$. The average of these force values after $1.75 \mathrm{~s}$ is considered to be the steady state rolling resistance force and is used to calculate the energy loss for the tire. In previous simulations, the simulation time was increased to around $8 \mathrm{~s}$ and it showed that the average value after reaching steady state did not change significantly after $3.5 \mathrm{~s}$ and as result this length of time is

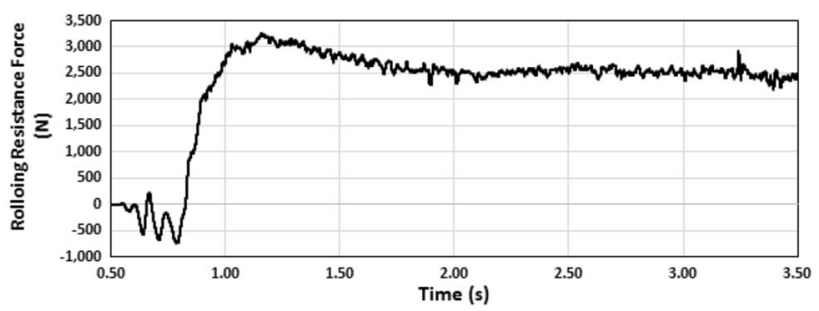

Fig. 14 Rolling resistance force as a function of tire at 40 psi inflation pressure and $4 \mathrm{kN}$ vertical load 


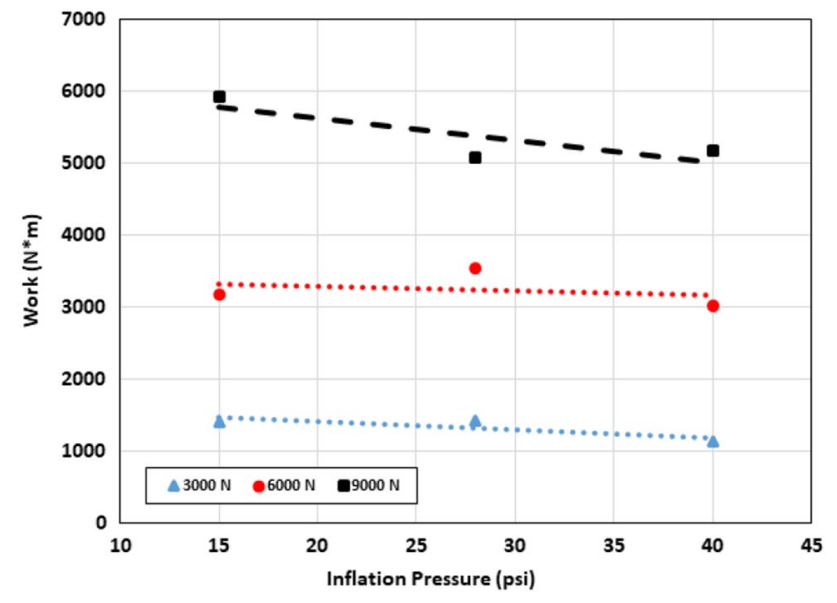

Fig. 15 Work done by the tire as a function of inflation pressure for several vertical loads

used to save computational time. Furthermore, the step computational time used within Pam-Crash is very small and a result there are a lot of output points generated from each output file. If the data points which cause the noise are deleted, the average rolling resistance force does not change at all due to having so many data points. Therefore, only the values which correspond to very large noise are deleted.

The work done by the tire is shown in Eq. 6 and is simply the multiplication of the distance the tire travels in $2 \mathrm{sec}-$ onds by the rolling resistance force. W presents the work done by the tire at a specific operating condition in N.m, $F_{r}$, presents the rolling resistance force in $N$, and $D$ is the distance traveled by the tire in $m$.

$W=F_{r} \times, D$

From Fig. 15 shows the variation of the work done by the HLFS tire over clayey loam soil as a function of inflation pressure for several applied vertical loads at a constant longitudinal speed of $1 \mathrm{~m} / \mathrm{s}$. It is observed that the work done by a free rolling tire on clayey loam sand is directly proportional to the vertical load applied on the tire. As the vertical load increases from 3000 to $9000 \mathrm{~N}$, the work done by the tire increases in similar increments at a constant inflation pressures and speed for a tire rolling for $2 \mathrm{~s}$. It is noted that as the vertical load increases, the rolling resistance force increases as well due to the higher sinkage (more contact area).

The inflation pressure is noticed to be indirectly proportional to the work done on the tire. As the inflation pressure is increased, the rolling resistance force is less and therefore the work done on the tire is also less. This is due to the ease of rolling for overinflated tire in clayey loam soil. The increase of inflation pressure will have a smaller contact patch between the tire and terrain and therefore it will be easier for the tire to be free rolling.

It is further noticed that the variation of the work done as a function of inflation pressure is almost the same for low vertical loaded. This is observed by looking into the slope of the work-pressure lines. The lines at low vertical load are almost parallel showing less effect of load on the rate of change of the work-pressure.

\section{Conclusions}

An FEA tire model of an agricultural tire size 220/70B16 was developed using Pam-Crash virtual environment. The FEA tire model consists of total of 42 lugs that were modeled using Mooney-Rivlin material. The modeled tire has 21 parts which make up the rim, tread, under tread, layered belts plies, and sidewalls. The rim was modeled as a rigid non-deformable body.

The tire was validated in static and dynamic response using the drum-cleat, vertical stiffness, lateral stiffness and longitudinal stiffness tests using measurement results provided by manufacturer. The first mode of vibration was computed to be around $67 \mathrm{~Hz}$ which falls in the normal range of agricultural tires. It was concluded that the FEA tire has a good presentation of the physical tire in lateral and longitudinal characteristics. Furthermore, the FEA tire has a good presentation of the vertical behavior at low vertical loads which is in the normal operating conditions.

The modeled tire will be used in further studies to compute the tire-compacted terrain interaction. The terrain will be modeled using smoothed-particle hydrodynamics (SPH) technique and the interaction will include the effect of multi-pass on the rolling resistance coefficient during free rolling at several operating conditions.

Acknowledgements The authors express their gratitude to NSERC Discovery Grant for funding this research work.

\section{Compliance with ethical standards}

Conflict of interest The authors declare that they have no conflict of interest.

\section{References}

1. Zorowski CF (1973) Mathematical prediction of dynamic tire behavior. Tire Sci Technol 1(1):99-117

2. Ridha RA (1974) Analysis for tire mold design. Tire Sci Technol 2(3): $195-210$

3. Tielking JT (1983) A finite element tire model. Tire Sci Technol 11(1):50-63 
4. Hu YK, Abeels PFJ (1994) Agricultural tire deformation in the 2D case by finite element methods. J Terramech 31(6):353-370

5. Burke AM, Olatunbosun OA (1997) New techniques in tyre modal analysis using MSC/NASTRAN. Int J Veh Design 18(2):203-212

6. Shoop S, Kestler K, Haehnel R (2006) Finite element modeling of tires on snow. Tire Sci Technol 34(1):2-37

7. Chae $S$ (2006) Nonlinear finite element modeling and analysis of a truck tire. PhD thesis, The Pennsylvania State University

8. Mohsenimanesh A, Ward SM, Owende POM, Javadi A (2009) Modelling of pneumatic tractor tyre interaction with multilayered soil. Biosyst Eng 104(2):191-198

9. Dhillon RS, Ali R, El-Gindy M, Philipps D, Oijer F, Johansson I (2013) Development of truck tire-soil interaction model using FEA and SPH. Technical report, SAE technical paper, 2013

10. Allen J, El-Gindy M, Koudela K (2009) Development of a rigid ring quarter-vehicle model with an advanced road profile algorithm for durability and ride comfort predictions. In: ASME 2008 international design engineering technical conferences and computers and information in engineering conference, pp 583-590. American Society of Mechanical Engineers Digital Collection, 2009

11. Slade JL (2009) Development of a new off-road rigid ring model for truck tires using finite element analysis techniques. Master's thesis, The Pennsylvania State University

12. Lescoe R (2019) Improvement of soil modeling in a tire-soil interaction using finite element analysis and smooth particle hydrodynamics. Master's thesis, The Pennsylvania State University

13. Dhillon RS (2013) Development of truck tire-terrain finite element analysis models. Master's thesis, University of Ontario Institute of Technology, Canada

14. El-Sayegh Z, El-Gindy M, Johansson I, Öijer F (2017) Truck tireterrain interaction modelling and testing: literature survey. Int J Veh Syst Model Test 12(3/4):163-216
15. El-Sayegh Zeinab, El-Gindy Moustafa, Johansson Inge, Öijer Fredrik (2018) Improved tire-soil interaction model using FEA-SPH simulation. J Terramech 78C:53-62

16. El-Sayegh Zeinab, El-Gindy Moustafa (2019) Modelling and prediction of tyre-snow interaction using finite element analysissmoothed particle hydrodynamics techniques. Proc Inst Mech Eng Part D J Automob Eng 233(7):1783-1792

17. Ragheb H, El-Gindy M, Kishawy H (2013) Development of a combat vehicle FEA tire model for off-road applications. Technical report, SAE technical paper

18. Dai H-H (1998) Model equations for nonlinear dispersive waves in a compressible Mooney-Rivlin rod. Acta Mech 127(1-4):193-207

19. HLFS agricultural tire (online). http://www.barez.com/trstire/24849-8.25-16.html. Accessed 05 Mar 2019

20. El-Sayegh Z, El-Gindy M, Johansson I, Öijer F (2018) Soft soil modeling using SPH technique for tire-soil interaction. ASME

21. Gheshlaghi F, El-Sayegh Z, Sharifi M, El-Gindy M (2020) Prediction and validation of an agricultural tire-soil interaction using advanced modelling techniques (under review). Tire Sci Technol

22. PAM System International (2014) Pam-Crash user manual version 2014. ESI Group, 2014

Publisher's Note Springer Nature remains neutral with regard to jurisdictional claims in published maps and institutional affiliations. 